\title{
INFLUÊNCIA DO BENEFICIAMENTO PÓS-COLHEITA NOS TEORES DE VITAMINA C E ACIDEZ DO ABACAXI PÉROLA
}

\author{
Taynara Silva de Castro ${ }^{1}$; Taliane Alves do Nascimento ${ }^{2}$; Nathália dos Santos da Silva ${ }^{3}$; \\ Jussara Raiza Silva ${ }^{4}$; Ivanderson Bruno de Sousa Marinho ${ }^{5}$; Tonye Gil Matos Waughon . \\ ${ }^{1}$ Discente do curso de Tecnologia Agroindustrial, Ênfase em alimentos, Universidade do Estado do Pará, Campus \\ Marabá, Bolsista PIBIC, taynaracastromarinho@ hotmail.com \\ ${ }^{2}$ Discente do curso de Tecnologia Agroindustrial, Ênfase em alimentos, Universidade do Estado do Pará, Campus \\ Marabá, talianenascimento@ hotmail.com. \\ ${ }^{3}$ Discente do curso de Tecnologia Agroindustrial, Ênfase em alimentos, Universidade do Estado do Pará, Campus \\ Marabá, nathalia.silva@hotmail.com \\ ${ }^{4}$ Discente do curso de Tecnologia Agroindustrial, Ênfase em alimentos, Universidade do Estado do Pará, Campus \\ Marabá, jussara_raiza@hotmail.com \\ ${ }^{5}$ Discente do curso de zootecnia, Universidade Federal do Tocantins, Araguaína, sousa_marinho@hotmail.com \\ ${ }^{6}$ Professor do curso de Tecnologia Agroindustrial, Ênfase em alimentos, Universidade do Estado do Pará, \\ tonyegil@hotmail.com
}

\begin{abstract}
RESUMO: O objetivo deste trabalho foi analisar os efeitos do processamento mínimo, sobre os frutos de abacaxi, após passarem pelos tratamentos de branqueamento e exposição à solução de ácido ascórbico e identificar dentre eles o de maior eficiência para a preservação das características sensoriais do abacaxi pérola. Foram analisadas acidez total e ácido ascórbico no fruto in natura e em dois dias de armazenamento a $10^{\circ} \mathrm{C}$ pelos quais se pode constatar que o fruto in natura e a formulação submetida à adição de ácido ascórbico se mantiveram mais estáveis.
\end{abstract}

PALAVRAS-CHAVE: Ananas comosus, conveniência, padrão de consumo.

\section{INFLUENCE OF POST-HARVEST PROCESSING IN ACID LEVELS OF VITAMIN C PINEAPPLE PEARL}

\begin{abstract}
The aim for this study was to examine the effects of minimal processing on pineapple fruits, after going through bleaching treatments and being exposure to the ascorbic solution acid, and identifying among them the highest efficiency for preservation of the sensory characteristics of the pineapple. Total acidity and ascorbic acid were analyzed in the still fresh fruit and in two days of $10{ }^{\circ} \mathrm{C}$ storage it is possible to see that the fresh fruit and the formulation subjected to the ascorbic acid remained stable.
\end{abstract}

KEY-WORDS: Ananas comosus, convenience, pattern of consumption.

\section{INTRODUÇÃO}

As vitaminas são essenciais para manter os processos metabólicos do organismo. Os seres humanos não fabricam algumas dessas vitaminas, entre elas o ácido ascórbico ou vitamina $\mathrm{C}$, por isso deve-se ingerir diariamente alimentos que sejam fonte da mesma (DOUGLAS apud NAVARRO, 2009). O Abacaxi (cru) possui um teor de 
10,3 mg/100g de ácido ascórbico do alimento (TACO, 2006).

Segundo Aquino et al. (2010), o fruto é proveniente das regiões tropicais e subtropicais e é muito consumido em todo o mundo, tanto ao natural quanto na forma de produtos industrializados. No Brasil, mais de 90\% do abacaxi produzido é consumido in natura, com perdas ao redor de $10 \%$ a $15 \%$ do produto colhido. Essa perda e a falta de incentivo para sua produção podem ser em parte, atribuídas à falta de conveniência dessa fruta, que exige descasque trabalhoso e com escorrimento de líquido, contenção em vasilhame adequado e equipamento próprio para consumo.

O presente trabalho tem como objetivo avaliar diferentes métodos de conservação e identificar dentre eles o de maior eficiência para a preservação das características sensoriais do abacaxi pérola, assim como constatar possível conservação do valor nutritivo do produto no que tange, preservação da Vitamina $\mathrm{C}$ e ácidos totais que proporcionam balanceamento ácido-base no organismo. Dentre os métodos de conservação utilizados encontram-se o processo de adição de ácido ascórbico para inibir o escurecimento enzimático, a sua ação se dá pelo abaixamento do $\mathrm{pH}$ do tecido do abacaxi, diminuindo assim a velocidade da reação do escurecimento enzimático; e o de branqueamento que com o uso de altas temperaturas inativa as enzimas que poderiam causar reações de deterioração, como o escurecimento.

\section{MATERIAL E MÉTODOS}

Foram utilizados frutos do abacaxizeiro (Ananas comosus) adquiridos no comércio de Marabá- PA.

Foram elaboradas três formulações de abacaxi, cada uma contendo três amostras, variando-se os métodos de conservação nas mesmas. Respectivamente nas formulações A, B e C, possuíam: ausência de conservantes, branqueamento e ácido ascórbico.

Para a preparação das amostras, após a recepção do fruto, foi feito a lavagem com detergente neutro e corte retirando parte da "coroa". Simultaneamente a solução de água clorada era preparada com concentração de $5 \mathrm{ml}$ de hipoclorito de sódio para 1L de água. O abacaxi permaneceu imerso na solução por 15 minutos.

Em seguida os abacaxis foram retirados da solução clorada e enxaguados em água corrente para então serem descascados manualmente com facas de ácido inoxidável sanificadas. Posteriormente os frutos foram cortados radialmente (em rodelas) em espessuras de $1,5 \mathrm{~cm}$ e novamente imersos em água clorada com concentração de $3 \mathrm{ml}$ de hipoclorito de sódio para cada $1 \mathrm{~L}$ de água. Após serem retirados desta solução os mesmos foram deixados em peneira para 
retirada do excesso de umidade, em seguida a remoção do eixo do broto (caule) seguindo para o processo de conservação pelo qual iam passar.

A amostra "A"(controle) que não sofreu nenhum método de conservação passou por retirada de umidade com papel toalha, foi embalado em bandeja de polietileno expandido, revestida com filme de PVC transparente e imediatamente armazenado sob ação de gelo.

A formulação B passou por um processo de branqueamento com água a $80{ }^{\circ} \mathrm{C}$ por 15 minutos. Aguardou-se a diminuição de temperatura, realizou-se a retirada de umidade com papel toalha e posterior embalagem com polietileno expandido, revestido com filme transparente de PVC, imediato armazenamento em isopor refrigerado com gelo.

Já a amostra C, foi submetida a ação de acido cítrico com concentração de 2000ppm por $1 \mathrm{~L}$ de água. Após imersos na solução de ácido cítrico por 10 minutos os frutos foram retirados, sofreram remoção de umidade, como os demais, foram embalados $\mathrm{e}$ armazenados.

As análises de ácido ascórbico (Vitamina C) e acidez total titulável no abacaxi foram efetuadas em triplicata imediatamente após o processamento no fruto in natura $\mathrm{e}$ ao primeiro e segundo dia de armazenamento, seguindo os procedimentos indicados pelas normas analíticas de Lutz (INSTITUTO ADOLFO LUTZ, 1985).

Todas as informações coletadas foram inseridas em um banco de dados relacional, utilizando o programa Microsoft Excel. A estatística descritiva foi utilizada através de procedimentos básicos como freqüência, e estimativa de parâmetros descritivos, como a tabela que serviu para a apresentação dos dados. Foram calculados a Média e o Desvio Padrão dos resultados das análises físicoquímicos.

\section{RESULTADOS E DISCUSSÃO}

A perda de vitamina $C$ pode se dar por lixiviação durante etapas de higienização dos alimentos, devido ao contato direto com a água. Além da sanitização, o descascamento, a retirada de folhas externas e o fatiamento de vegetais são responsáveis pela remoção de vitaminas associadas aos tecidos superficiais e à exposição das vitaminas localizadas nos tecidos internos a fatores relacionados com as perdas, como oxigênio e luz (MAIA et al., 2008).

O teor de ácido ascórbico na amostra A (controle) reduziu ao longo do armazenamento, resultado esperado, tendo em vista que este ácido é extremamente instável e perde suas propriedades na presença de ar, calor, água ou luz, fatores que se apresentaram durante a realização das análises. 
A mesma redução foi constatada na amostra B (branqueamento) Além dos fatores já citados ela pode ser oriunda do processo de branqueamento, onde é utilizada alta temperatura, que causa degradação da vitamina, haja vista que a mesma é termossensível assim como Silva et al (2008) afirmam, que a oxidação do ácido ascórbico é influenciada principalmente com a elevação da temperatura.

A amostra C (adição de ácido ascórbico) mesmo sendo submetida ao tratamento de adição de ácido ascórbico (antioxidante) sofreu um decréscimo no teor de vitamina $C$; isto ocorreu possivelmente segundo Lima et al (2009) citados por Navarro devido dissolver-se facilmente em água $(0,3 \mathrm{~g} / \mathrm{mL})$, e quando dissolvida, torna-se muito sensível ao oxigênio, luz, temperatura, meio alcalino. A tabela 1 demonstra a perda de vitamina $C$ nas três amostras durante os dias de análise.

Tabela 1. Teor de vitamina $\mathrm{C}(\mathrm{mg} / \mathrm{ml})$ e \% ácidos totais das amostras $\mathrm{A}, \mathrm{B}$ e C de abacaxi pérola, com as respectivas formulações: ausência de conservantes, branqueamento e ácido ascórbico. Durante os dias 0, 1 e 2 de análise, Marabá, 2010.

\begin{tabular}{ccccc}
\hline \multirow{2}{*}{ Amostras/dias } & \multicolumn{2}{c}{ Determinação de Ácido ascórbico $(\mathrm{mg} / \mathrm{ml})$} & \multicolumn{2}{c}{ Determinação de Ácidos Totais (\%) } \\
\cline { 2 - 5 } & Média & D.P & Média & D.P \\
\hline A/0 & 4,381333 & 0,122398257 & 1,226667 & 0,06350853 \\
B/0 & 3,321333 & 0,244796514 & 1,453333 & 0,215715862 \\
$\mathrm{C} / 0$ & 2,826667 & 0,122398257 & 1,7 & 0 \\
& & & & 0,196299092 \\
$\mathrm{~A} / 1$ & 2,035667 & 0,080251687 & 1,303333 & 0,098149546 \\
$\mathrm{~B} / 1$ & 1,943 & 0,139 & 0,793333 & 0 \\
$\mathrm{C} / 1$ & 1,388 & 0 & 0,85 & 0,17 \\
& & & & 0,196299092 \\
$\mathrm{~A} / 2$ & 1,590667 & 0,132500314 & 1,53 & 0,098149546 \\
$\mathrm{~B} / 2$ & 1,325667 & 0,108186054 & 1,246667 & \\
$\mathrm{C} / 2$ & 1,856667 & 0,132001263 & 1,643333 & \\
\hline
\end{tabular}

Legenda: D.P= Desvio Padrão.

Enquanto a amostra A preservou sua concentração ácida do fruto ainda in natura ao primeiro dia de armazenamento as amostras B e C sofreram um decréscimo de sua acidez, justificado pelos processos aos quais foram submetidas no intuito de conservação, e a sensibilidade dos ácidos orgânicos a tais processos. No entanto há uma 
alteração conjunta entre as amostras do primeiro ao segundo dia de armazenamento onde sofrem uma elevação ácida. A tabela 1 revela a concentração de ácidos tostais nas amostras durante os três dias de análise.

\section{CONCLUSÕES}

Dentre os processos de conservação pelos quais passaram o abacaxi minimamente processado nesse trabalho, os que demonstraram maior eficiência enquanto manutenção do teor de vitamina $\mathrm{C}$ foram os que sofreram adição de ácido ascórbico e a amostra controle (conservada apenas pela temperatura baixa agrediu em menor proporção as características do fruto) $\mathrm{O}$ processo de branqueamento por sua vez, com a utilização de altas temperaturas foi o que mais prejudicou essa vitamina termossensível.

\section{REFERÊNCIAS}

AQUINO, A et al. Alimentos processados.

Disponível em:

$<$ http://br.monografias.com/trabalhos2/alimen

tos-processados/alimentos-

processados2.shtml>. Acesso em: 22 mar. 2010.
INSTITUTO ADOLFO LUTZ. Normas Analíticas do Instituto Adolfo Lutz. São Paulo, IMESP, $3^{\mathrm{a}}$ ed., v. 1: Métodos químicos e físicos p/ análise de alimentos. 1985.

MAIA, G. E. G., et al. Determinação dos teores de vitamina c em hortaliças minimamente processadas. Alimentos e Nutrição, Araraquara v.19, n.3, p. 329 - 335, jul./set. 2008.

NAVARRO, A. A. Determinação de ácido ascórbico em sucos de goiaba industrializados. Projeto do Trabalho de Conclusão de Curso (Graduação). Curso Superior de Tecnologia em Alimentos da Universidade Tecnológica Federal do Paraná - UTFPR, Londrina, 2009.

SILVA, A. S. et al. Desidratação da polpa de tamarindo pelo Método de camada de espuma. Ciência Agro tecnologia, Lavras, v. 32, n. 6, p. 1899-1905, nov./dez., 2008.

TABELA BRASILEIRA DE COMPOSIÇÃO DE ALIMENTOS- TACO. Versão 2. Campinas, 2006. Disponível em: <www.unicamp.br/nepa/taco/tabela>. Acesso em: 14 mai. 2011. 